\title{
Bladder rehabilitation with dorsal rhizotomy and ventral neuroprosthesis
}

\author{
L S Baskin MD, R A Schmidt MD* \\ Department of Urology, University of California School of Medicine, San Francisco, \\ California, CA 94143-0738, USA.
}

Two patients with severe neuropathic bladders were successfully treated with selective dorsal rhizotomy in conjunction with a ventral root neuroprosthesis. Both patients achieved stabilization of their renal function, continence, resolution of vesicoureteral reflux, and relief from indwelling urethral catheters. This alternative form of management avoids the complications of other operative approaches.

\section{Keywords: neuropathic bladder; dorsal rhizotomy; neuroprosthesis; ventral root stimulation.}

\section{Introduction}

Patients with neuropathic bladders are at risk for urinary tract infections, vesicoureteral reflux, pyelonephritis, renal damage and urinary calculi. The goal of any treatment program is to prevent these complications while preserving urinary continence. This can be accomplished by maintaining a low pressure bladder with ade quate storage capacity. Initially, pharmaco logical treatment is indicated, ${ }^{1}$ and anticho linergic medication has been quite effective in both neonates and adults. ${ }^{2}$ Clean intermittent catheterization can reliably and safely empty the bladder. ${ }^{3}$

Some patients, however, will not respond to conservative treatment and are managed with chronic indwelling urethral catheters, incurring the risk of serious complications such as recurrent cystitis, pyelonephritis, urinary calculi, fistulas, renal deterioration and necrotizing soft tissue infections. ${ }^{4}$ Another option is operative intervention, which includes conduit urinary diversions, continent urinary reservoirs, bladder augmentations and/or sphincteric ablation.

In this paper, we report an alternative form of bladder rehabilitation, in 2 patients (one man and one woman) with severe neuropathic bladders. Conservative treatment failed and they were suffering from the complications of continuous urethral catheter drainage. These 2 patients were

${ }^{*}$ Correspondence. chosen from a larger group of patients presently treated at the University of California, San Francisco, for neuropathic voiding dysfunction. The patients were selected, as an interim study, to illustrate both successful short term treatment as well as long term follow up (the short term follow up of case 2 in this study was previously reported (case 5 in reference 13)).

In both patients, selective sacral root dorsal rhizotomy produced a flaccid, low pressure, large capacity bladder. In addition, bladder emptying was achieved through implantation of a neuroprosthesis. An electrode was attached to ventral sacral nerve roots, thereby allowing transcutaneous neurostimulation of the bladder, initiating a contraction with subsequent controlled voiding.

\section{Case 1}

A 35 year old man suffered a traumatic injury to his spinal cord at the T4 level, resulting in complete motor paralysis and a mixed sensory defect. The patient attempted to manage his bladder by manual percussion of the lower abdomen thereby triggering voiding. Four years after the injury he developed renal failure with a creatinine level of $9.0 \mathrm{mg} / \mathrm{dl}$, and sepsis. He was treated with an indwelling urethral catheter (16 French) and intravenous antibiotics. His sepsis cleared and the creatinine fell to $3.8 \mathrm{mg} / \mathrm{dl}$. Urodynamic and radiographic evaluation revealed a small, non- 
compliant bladder with severe bilateral vesico-ureteral reflux (Fig 1). Attempts at management with intermittent catheterization and anticholinergic medication failed secondary to an abrupt increase in serum creatinine when the urethral catheter was removed. Distal sphincterotomy or pudendal neuroectomy were not performed. Chronic management (one year) with the indwelling urethral catheter (16 French) led to recurrent episodes of urosepsis.

Operative intervention was considered, with a number of options possible (Table I). We chose an alternate form of bladder rehabilitation on this high risk patient with baseline renal failure. Bilateral selective dorsal rhizotomy (extradural) of sacral roots S2, S3, and S4 was performed. Concurrently, neuroprosthetic electrodes were attached to the ventral roots of S3 and S4 for subsequent direct bladder stimulation and emptying.

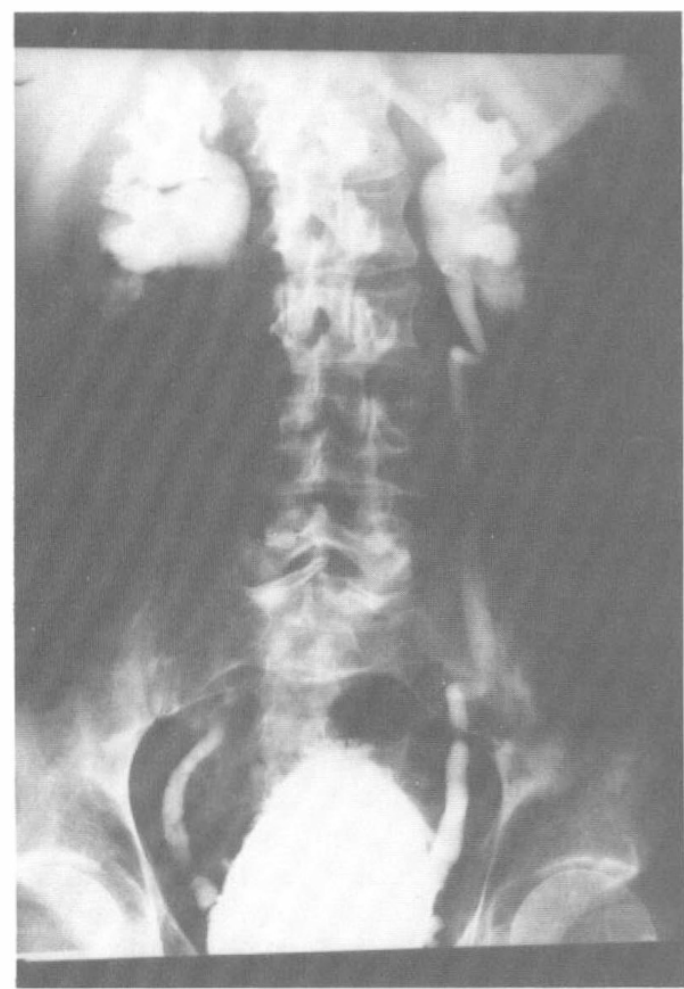

Figure 1 Case 1. Preoperative cystogram demonstrating a noncompliant bladder with severe bilateral vesicoureteral reflux.
Table I Options for the operative management of the severe neuropathic bladder

Augmentation cystoplasty

Ileo-conduit urinary diversion

Continent urinary reservoir

Gastric augmentation/reservoir

Postoperatively, the patient's bladder changed from a small capacity, high pressure reservoir to a large capacity $(400 \mathrm{ml})$ low pressure reservoir with almost complete resolution of severe bilateral reflux (Fig 2). Urodynamic studies confirm a decrease in bladder preasure from $>40 \mathrm{~cm} \mathrm{H}_{2} \mathrm{O}(100 \mathrm{cc}$ volume) preoperatively to a maximum of $15 \mathrm{~cm} \mathrm{H}_{2} \mathrm{O}$ postoperatively. The patient voids (Fig 3 ) by initiating a bladder contraction (Fig 4) via the neuroprosthesis, which is activated by a radio frequency inductive link

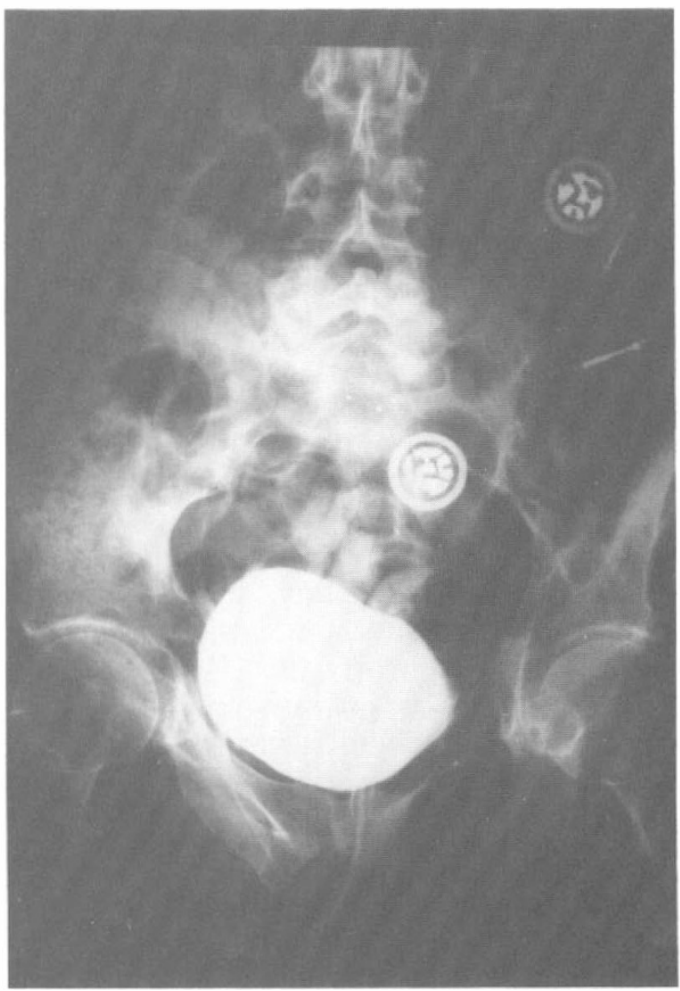

Figure 2 Case 1. Postoperative cystogram demonstrating a large capacity bladder with almost complete resolution of severe bilateral reflux (grade I on right). Note neuroprosthesis and sacral root electrodes in place. 
across the skin. The patient uses a continuous train of pulses determined by urodynamic testing 3-6 weeks postoperatively (typical parameters (which can vary with the impedance of the implanted electrode) are $5 \mathrm{~mA}, 15 \mathrm{~Hz}$ and a pulse width of $180 \mathrm{usec}$ ).

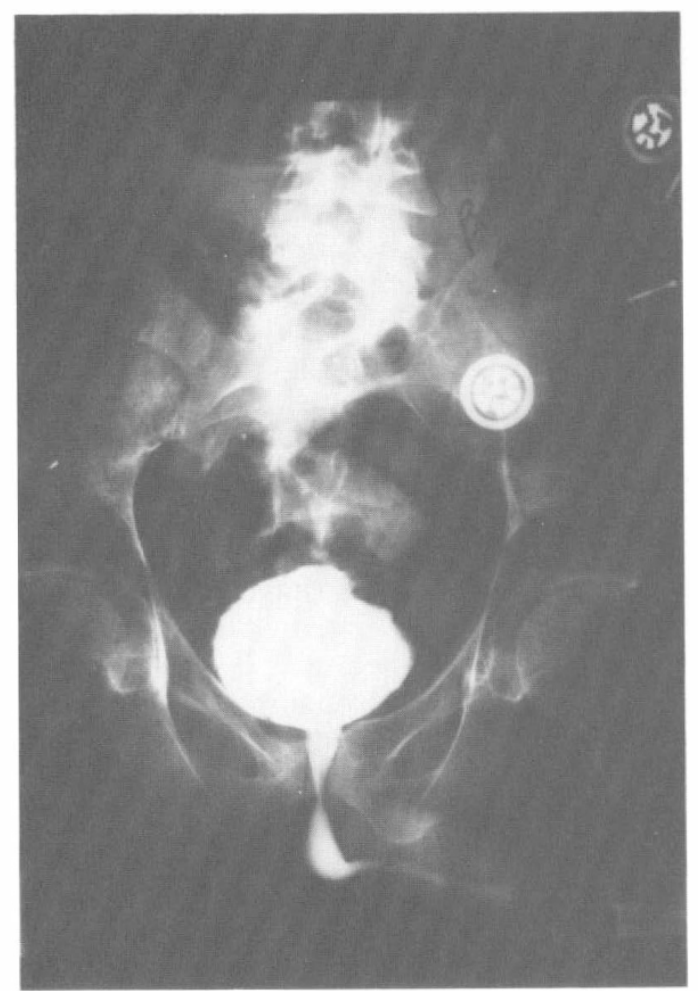

Figure 3 Case 1. Voiding cystourethrogram initiated via neuroprosthesis.

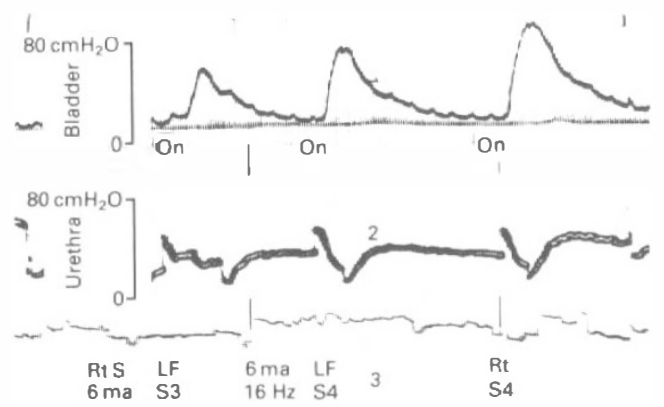

Figure 4 Case 1. Results of urodynamic studies showing 3 bladder contractions initiated (represented by 'On') by the neuroprothesis. Note initial simultaneous increase in urethral pressure (sphincter), then relaxation.
He typically voids 6 times per day and once in the middle of the night, the impetus being a feeling of lower abdominal fullness or adherence to a regimen of timed voiding. His post void residual urine values remain $<30 \mathrm{ml}$, his creatinine level has been stable at $3.4 \mathrm{mg} / \mathrm{dl}$, and he remains free of infection. The patient states that he has psychogenic erections. Objective erectile function studies have not been obtained.

\section{Case 2}

A 24 year old woman developed transverse myelitis, subsequently resulting in a T8 paraplegia. Rehabilitation of her urinary tract proved difficult secondary to a small hyperreflexic bladder. Persistent urinary incontinence despite anticholinergic medication led to the use of a chronic indwelling urethral catheter. Despite continuous catheter drainage, the extreme bladder spasticity led to progressive hydroureteronephrosis and urinary leakage around the catheter. At age 28, operative management was considered (Table I).

An alternative form of bladder rehabilitation was chosen. Selective dorsal rhizotomies (extradural) of right S2, S3 and S4 were performed along with simultaneous implantation of neuroprosthetic electrodes on the ventral aspect of the right S3 root and the intact left $\mathrm{S} 3$ root.

Postoperatively the patient's bladder has changed to a large capacity, low pressure reservoir. She has been dry without an indwelling urethral catheter, and her hydroureteronephrosis has resolved. Seven-year follow up reveals that the patient continues to void every 2.5 to 3 hours either by transcutaneous neurostimulation of a bladder contraction or by intermittent self catheterization.

\section{Discussion}

The neurologically damaged urinary bladder has the potential to determine the fate of the upper urinary tract. Without proper management, the majority of patients with spinal cord injuries will die from renal failure. ${ }^{5}$ Upper tract deterioration can be prevented by ensuring a low pressure, large 
capacity bladder. This ideal situation will also prevent lower tract complications such as infection, incontinence, calculi and vesicoureteral reflux. In some patients this can be achieved pharmacologically in conjunction with intermittent self catheterization; ${ }^{6}$ in others, external sphincterotomy, although requiring a continuous external collection device, will provide a low pressure, infection free urinary tract. ${ }^{7}$

Another approach has been surgical (Table I), either bladder augmentation with bowel, urinary diversion requiring an external appliance, or the creation of a continent urinary reservoir. The use of bowel in urological surgery has been well tested but is not without complications. Ileo-conduit urinary diversion, considered the gold standard, suffers from late complications such as ileal loop stenosis, ureteroileal strictures and upper tract deterioration. 8.9 More recently, there have been reports of spontaneous perforations in augmentation cystoplasties. ${ }^{10}$ Additionally, the final word concerning the malignant potential of bowel when transposed into the urinary tract remains to be written. ${ }^{11}$

An alternative approach in the management of the severe neuropathic bladder is illustrated by these 2 patients. Selective sacral root dorsal rhizotomy in conjunction with implantation of a ventral sacral root neuroprosthesis produces a low pressure, large capacity bladder with controlled voiding initiated by transcutaneous neurostimulation.

Electrical stimulation has been successfully applied in patients with spinal cord injuries and those with severe neuropathic voiding disorders. ${ }^{12-16}$ In conjunction with selective dorsal rhizotomy, it achieves a low pressure reservoir. ${ }^{17-19}$

Selective dorsal rhizotomy also reduces detrusor hyperreflexia, leading to an increase in bladder capacity. It also diminishes the spasticity of the pelvic floor and external sphincter, improving the response to ventral root electrical stimulation. ${ }^{12,18,19}$ Preoperatively, the response to selective dorsal rhizo- tomy can be assessed by temporary percutaneous nerve blocks. Patients whose bladder capacity greatly increases or whose uninhibited contractions subside are candidates for further therapy.

Theoretically, selective dorsal rhizotomy puts male patients at risk for permanent postoperative neurogenic impotence. ${ }^{13} \mathrm{Un}$ fortunately, at the present time it is impossible to predict which patients will lose erectile function. Careful preoperative consent is clearly necessary.

Bladder emptying in patients with dorsal rhizotomy can be accomplished by timed, intermittent self catheterization. A more physiological approach is to take advantage of the intact lower urinary tract that no longer has control from the central nervous system but can be influenced by direct electrical stimulation. Knowledge of the neurophysiology of micturition and careful anatomical studies of the sacral nerve roots, pelvic floor and bladder have allowed electrical stimulation to become more than a laboratory phenomenon. ${ }^{20-22}$ Neuroprostheses for bladder rehabilitation, severe voiding dysfunction and pelvic pain have proven safe and effective. ${ }^{13,15,16}$ In both patients voiding is accomplished by transcutaneous electrical stimulation of the ventral sacral nerve roots, precipitating a reproducible bladder contraction with subsequent bladder emptying.

These two cases illustrate an alternative approach to the severe neuropathic bladder that avoids the complications of other treatment options. In both patients, the severity of their bladder dysfunction was manifested by upper tract decompensation from vesicoureteral reflux and recurrent infections. Selective dorsal rhizotomy stabilized the upper tracts in both patients, allowed controlled voiding, and eliminated the need for chronic indwelling catheterization. The successful use of dorsal rhizotomy and a ventral root neuroprosthesis will not only decrease morbidity in patients with a neuropathic bladder but dramatically improve lifestyle and self image.

\section{References}

1 Herschorn S (1990) The management of neurogenic bladder dysfunction: emphasis on pharmacologic manipulation and intermittent catheterization. In Webster GR, Stone AR, editors. Problems in Urology. 
Vol 4, No 1. Lippincott Co, Philadelphia.

2 Baskin LS, Kogan BA, Bernard F (1990) Treatment of neonatal neurogenic bladder. Dysfunction with anticholinergic drugs and intermittent catheterization. Br J Urol 66: 532-534.

3 Guttman L, Frankel H (1966) The value of intermittent catheterization in the early management of paraplegia and tetraplegia. Paraplegia 4: 63-67.

4 Jacobs SC, Kaufman JM (1978) Complications of permanent bladder catheter drainage in spinal cord injury patients. J Urol 119: 740-741.

5 Barber KE, Cross RR Jr (1952) The urinary tract as a cause of death in paraplegia. J Urol 67: 494-502.

6 McGuire EJ, Savastano JA (1983) Long-term followup of spinal cord injured patients managed by intermittent catheterization. J Urol 129: 775-776.

7 Malament M (1972) External sphincterotomy in neurogenic bladder dysfunction. J Urol 108: 554-557.

8 Mitchell ME, Yoder IC, Pfister RC, Daly J, Althausen A (1977) Ileal loop stenosis: A late complication of urinary diversion. J Urol 118: 957-961.

9 Shapiro SS, Lebowitz R, Colodny AH (1975) Fate of 90 children with ileal conduit urinary diversion a decade later: analysis of complications, pyelography, renal function and bacteriology. J Urol 114: 289-295.

10 Sheiner JR, Kaplin GW (1988) Spontaneous bladder rupture following enterocystoplasty. J Urol 140: 1157-1158.

11 Filmer RB (1987) Malignancy following bladder augmentations. Dialogues Pediat Urol 10: 7-8.

12 Tanagho EA, Schmidt RA (1988) Electrical stimulation in the clinical management of the neurogenic bladder. J Urol 140: 1331-1339.

13 Tanagho EA, Schmidt RA, Orvis BR (1989) Neural stimulation for control of voiding dysfunction: a preliminary report in 22 patients with serious neuropathic voiding disorders. J Urol 142: 340-345.

14 Schmidt RA (1986) Advances in genitourinary neurostimulation. Neurosurgery 18: 1041-1044.

15 Brindley GS, Poleky CE, Rushton DN (1982) Sacralanterior root stimulator for bladder control in paraplegia. Paraplegia 20: 365-381.

16 Brindley GS, Rushton DN (1990) Long-term follow-up of patients with sacral anterior root stimulator implants. Paraplegia 28: 469-475.

17 Diokno AC, Vinson RK, McGillicuddy J (1977) Treatment of the severe uininhibited neurogenic bladder by selective sacral rhizotomy. J Urol 118: 299-301.

18 Sauerwein D (1990) Die operative Behandlung der spastischen Blasenlahmung bei Querschnittlahmung. Urologe (A) 29: 196-203.

19 MacDonagh RP, Forster DMC, Thomas DG (1990) Urinary continence in spinal injury patients following complete sacral posterior rhizotomy. Br J Urol 66: 618-622.

20 Juenemann K-P, Lue TF, Schmidt RA, Tanagho EA (1988) Clinical significance of sacral and pudendal nerve anatomy. J Urol 139: 74-80.

21 Schmidt RA, Bruschini H, van Gool J, Tanagho EA (1979) Micturition and the male genitourinary response to sacral root stimulation. Invest Urol 17: 125-129.

22 Schmidt RA, Bruschini H, Tanagho EA (1979) Urinary bladder and sphincter responses to stimulation of dorsal and ventral sacral roots. Invest Urol 16: 300-304. 